\title{
ACUTE ORAL TOXICITY OF CAPSAICIN IN MICE AND RATS
}

\author{
Akemi SAITO and Masaharu YAMAMOTO \\ Department of Hygiene and Preventive Medicine, \\ Niigata University School of Medicine, \\ 1 Asahimachi-dori, Niigata city, Niigata 951, Japan
}

(Received April 24, 1996 ; Accepted August 6, 1996)

\begin{abstract}
The oral toxicity of capsaicin was investigated in mice and rats. Oral $\mathrm{LD}_{50}$ values were $118.8 \mathrm{mg} / \mathrm{kg}$ for male and $97.4 \mathrm{mg} / \mathrm{kg}$ for female mice, and 161.2 $\mathrm{mg} / \mathrm{kg}$ for male and $148.1 \mathrm{mg} / \mathrm{kg}$ for female rats. Major toxic symptoms in mice were salivation, erythema of skin, staggering gait, bradypnea and cyanosis. Some animals showed tremor, clonic convulsion, dyspnea and lateral or prone position and then died 4 to $26 \mathrm{~min}$ after dosing. Survivors recovered within $6 \mathrm{hr}$ in mice and $24 \mathrm{hr}$ in rats. Toxic symptoms of rats were almost the same as mice, but rats showing higher incidence of cyanosis, clonic or tonic convulsion, dyspnea and lateral position, and the recovery was later than mice. The cause of death by capsaicin may be due to hypotension and respiratory paralysis in both animals, although the pathophysiology of death is not clearly understood. At pathological examination, erosion and ulcer of gastric fundus were seen in dead animals, while no pathological change was seen in surviving ones.
\end{abstract}

KEY WORDS : Capsaicin, Acute toxicity, $\mathrm{LD}_{50}$, Mouse, Rat

\section{INTRODUCTION}

Capsaicin is a major agent present in various species of capsicum fruits. Since the people living in South America and Southeast Asia take large amounts of capsicum fruits, the toxicity of capsicum fruits has been a matter of concern.

With regard to the toxicity of capsaicin in capsicum fruits, the following information has been reported by many investigators. Nagabhushan and Bhide (1985) demonstrated that capsaicin exerted the mutagenicity in both Ames and micronucleous tests. Toth et al. (1984) reported that capsaicin caused adenocarcinoma to the duodenum, Agrawal et al. (1986) also reported that chili extract acted as a promoter for stomach

Correspondence : Akemi SAITO at the above address.

Present address : Hokuriku Seiyaku Co., Ltd.

37-1-1 Inokuchi, Katsuyama city, Fukui 911, Japan and liver tumors. In human cases, LópezCarrillo et al. (1994) conducted a case-control study of gastric cancer in Mexico and suspected chili consumption may be a strong risk factor for gastric cancer. A recent case-control study in Chile indicated that chili pepper consumption may be a risk factor for gallbladder cancer (Serra et al. 1996).

As one of the pharmacological effects, Jancsó et al. (1977) reported that capsaicin, given to newborn rats, induces selective degeneration of a distinct population of primary sensory neurons involved in mediation of chemogenic pain. Konishi (1984) summarized capsaicin acts to sensory nerve endings, a part of autonomic nerve and the spinal cord according to releasing the substance $P$, and is in general use as tool of neurological experiment. Holzer, P. (1991) investigated the cellular target and mechanism of the actions of capsaicin and attempted to address the practical value of capsaicin as a pharmacolo- 
gical research tool and to point out the limitations of its usefulness.

Some beneficial effects of capsaicin, however, have been noted. Jang et al. (1989) demonstrated that capsaicin inhibited benzopyrene or dimethylbenzanthracene-induced mice lung adenoma development. Recently, Kang et al. (1995) confirmed that capsaicin reduced the occurrence of ethanol-induced gastric ulcer in rats. Surh and Lee (1995) reviewed the effect of capsaicin as a double edged sword.

Considering all the above facts, the character of capsaicin has been investigated well, but toxicological profiles of oral treatment with large amounts of capsaicin to rats and the relation between toxicology and epidemiology are not sufficiently clarified yet. As the first step to conduct a series of further toxicological studies, the oral acute toxicity study of capsaicin was undertaken with comparison between mice and rats for the first time.

\section{MATERIALS AND METHODS}

\section{Animals and Chemicals}

A total of 120 mice and 120 rats, six weekold Crj : ICR mice weighing 24 to $30 \mathrm{~g}$ for males and 19 to 26 for females and six week-old Crj : $\mathrm{CD}$ rats weighing 149 to $174 \mathrm{~g}$ for males and 117 to $138 \mathrm{~g}$ for females from Charles River Japan Inc. (Shiga, Japan) were utilized for this study. All of them were housed at a maximum of 5 to a polycarbonated cage with white chips as bedding in an air-conditioned animal room (temperature ; $24 \pm 3^{\circ} \mathrm{C}$; relative humidity, $60 \pm 10 \%$; lighting cycle, $12 \mathrm{~h}$ light $/ 12 \mathrm{~h}$ dark cycle) and allowed free access to commercially available diet (CRF-1, Oriental Yeast Co. Ltd., Tokyo, Japan) and tap water. All animals were fasted overnight prior to dosing.

Capsaicin $\left(\mathrm{C}_{17} \mathrm{H}_{27} \mathrm{NO}_{3}\right.$, MW : 293.41, synthesis) was obtained from Tokyo Kasei Kogyo Co. Ltd. (Tokyo, Japan) and was crashed by a mortar, dissolved with propylene glycol (Wako Pure Chemical Industries, Ltd.).

2. Experimental design and performance.

Capsaicin was singly administered at five dose levels of $96,116,139,167$ and $200 \mathrm{mg} / \mathrm{kg}$ to mice and rats each. These doses were selected based on the preliminary studies using a smaller number of animals, and also on the previous studies (Glinsukon et al., 1980). Each group consisted of 10 males and 10 females. The dosage volume was $10 \mathrm{ml} / \mathrm{kg}$ by gavage. Control animals received vehicle (propylene glycol).

Clinical signs were observed for 7 days after single administration. Body weights were measured at 1, 3 and 7 days after treatment. All animals were necropsied after death or on Day 8 and gross changes were recorded. Stomach, liver, gallbladder (mouse only) and kidney were fixed in $10 \%$ neutral buffered formalin and processed for histopathological examination. Stomach and gallbladder were examined because chili consumption may be a risk factor for gastric and gallbladder cancer (López-Carrillo et al., 1994, Serra et al., 1996). Liver and kidney were examined by taking account of their important role on the metabolism and excretion of capsaicin, respectively. Paraffin section was made and stained with hematoxylin and eosin. In addition, PAS stain was conducted for the stomach section.

$\mathrm{LD}_{50}$ values were calculated by Probit method based on mortality during the 7-day observation period. The significance of intergroup differences of body weights and body weight gains were assessed using Bartlett's test by calculating group means and deviations.

\section{RESULTS}

The incidence of death in each group and $\mathrm{LD}_{50}$ values are shown in Table 1.

More than $60 \%$ of mice $(6 / 10 \sim 9 / 10)$ died in all the groups except for the 96 and $116 \mathrm{mg} / \mathrm{kg}$ groups of males $(4 / 10) . \quad \mathrm{LD}_{50}$ values were 118.8 $\mathrm{mg} / \mathrm{kg}$ (95\% confidence limits : 96.9 145.6) for males and $97.4 \mathrm{mg} / \mathrm{kg}(68.8 \sim 137.4)$ for females. In rats, the death was observed in dosedependent manner in all the treated groups. $\mathrm{LD}_{50}$ values were $161.2 \mathrm{mg} / \mathrm{kg}(126.1 \sim 206.3)$ and $148.1 \mathrm{mg} / \mathrm{kg}(120.5 \sim 182.1)$, respectively. The deaths occurred between 4 to 26 min after dosing in both mice and rats.

In mice, salivation appeared immediately after the treatment, and convulsion, erythema of skin followed within ten minutes. Some animals showed tremor, clonic convulsion, staggering gait, bradypnea and prone position. These 
Table 1. Mortality and $L D_{50}$ values of capsaicin after a single oral administration in mice and rats.

\begin{tabular}{|c|c|c|c|c|}
\hline Animal & Sex & $\begin{array}{c}\text { Dose } \\
(\mathrm{mg} / \mathrm{kg})\end{array}$ & Mortality & $\begin{array}{c}\mathrm{LD}_{50}(\mathrm{mg} / \mathrm{kg}) \\
(95 \% \text { confidence limits })\end{array}$ \\
\hline \multirow[t]{10}{*}{ Mice } & male & 96 & $4 / 10$ & \multirow{5}{*}{$\begin{array}{c}118.8 \\
(96.9-145.6)\end{array}$} \\
\hline & & 116 & $4 / 10$ & \\
\hline & & 139 & $7 / 10$ & \\
\hline & & 167 & $6 / 10$ & \\
\hline & & 200 & $9 / 10$ & \\
\hline & \multirow[t]{5}{*}{ female } & 96 & $5 / 10$ & \multirow{5}{*}{$\begin{array}{c}97.4 \\
(68.8-137.4)\end{array}$} \\
\hline & & 116 & $6 / 10$ & \\
\hline & & 139 & $6 / 10$ & \\
\hline & & 167 & $7 / 10$ & \\
\hline & & 200 & $8 / 10$ & \\
\hline \multirow[t]{10}{*}{ Rats } & male & 96 & $2 / 10$ & \multirow{5}{*}{$\begin{array}{c}161.2 \\
(126.1-206.3)\end{array}$} \\
\hline & & 116 & $3 / 10$ & \\
\hline & & 139 & $5 / 10$ & \\
\hline & & 167 & $5 / 10$ & \\
\hline & & 200 & $6 / 10$ & \\
\hline & \multirow[t]{5}{*}{ female } & 96 & $2 / 10$ & \multirow{5}{*}{$\begin{array}{c}148.1 \\
(120.5-182.1)\end{array}$} \\
\hline & & 116 & $3 / 10$ & \\
\hline & & 139 & $6 / 10$ & \\
\hline & & 167 & $5 / 10$ & \\
\hline & & 200 & $7 / 10$ & \\
\hline
\end{tabular}

symptoms were also evident in survivors, but disappeared $6 \mathrm{hr}$ after the treatment. In the case of dying animals, tonic convulsion, dyspnea, cyanosis and lateral position were frequently found, and the death occurred within 4 to $10 \mathrm{~min}$. The occurrence of the last death was 26 min after the treatment.

In rats, they showed the same signs as those of mice, but clonic convulsion, cyanosis, lateral position and dyspnea were found more frequently as compared with mice. All symptoms appeared within ten min except staggering gait. Many animals in higher dose groups showed tonic convulsion, dyspnea and cyanosis and died 4 to 26 min after dosing. In survivors, these symptoms disappeared after $24 \mathrm{hr}$.

In both mice and rats, body weight gains were comparable with those in the control group (data not shown).

At necropsy, hemorrhage of gastric fundus was seen in some of the dead animals. No significant macroscopic changes were observed in the liver, gallbladder (mouse only) and kidney. Surviving animals did not show any pathological changes.

At histopathology, the stomach of all the dead animals had focal slight erosion or ulcer with increased mucus. Other organs appeared almost normal both in the dead and surviving animals.

\section{DISCUSSION}

In the present study, we found that capsaicin-treated animals showed salivation, convulsion, erythema of skin and bladypnea just after dosing. The death occurred within 26 min both in mice and rats. Signs such as dyspnea and cyanosis after convulsion were seen prior to death. No differences were noted between males and females. Capsaicin is known to cause hypotension and respiratory paralysis, though the 
mechanism by which capsaicin acts is not yet known (Glinsukon et al. 1980). Hypotension was also reported in dogs (Lille and Ramíez, 1935), cats (Toh et al., 1955) and rabbits (Toda et $a l .$, 1972). The cause of death may be due to hypotension and respiratory paralysis, although pathophisiology of death is not clearly understood. Pharmacological actions of capsaicin have been reported by many investigators (Jancsó et al., 1977, Konishi, 1984, Holzer, 1991). They thought that one of the acute effects of capsaicin is excitation of primary afferent neurons at high potency, and concluded that unmyelinated afferent neurons are capsaicin sensitive. They also indicated that the neurones containing Substance $\mathrm{P}$, Calcitonin gene-related peptide and the other peptide markers are sensitive as well. There might be some relationship between these pharmacological actions and clinical signs in this study. However, considering the fact that convulsion and bradypnea are frequently encountered as a non-specific sign when a large dose of test substance is given to rodents, it may be difficult to draw definite conclusions that these signs are due to neurological effects.

To the best of our knowledge, there is only one report on $\mathrm{LD}_{50}$ of capsaicin. Glinsukon et al. (1980) reported the acute toxicity of capsaicin, as shown in Table 2. They treated capsaicin by intraperitoneal route to various species, and by various routes to mice in order to determine $\mathrm{LD}_{50}$. Therefore, we thought that it would be very significant to evaluate the toxicity using the same route as human intake, and attempted to evaluate the oral acute toxicity in detail using both sexes of mice and rats. This is the first report to determine the oral acute toxicity in rats. In the experiment conducted by Glinsukon et al. (1980), oral $\mathrm{LD}_{50}$ value of male mice was 190 $\mathrm{mg} / \mathrm{kg}$, without any clinical signs, and the value was found to be slightly higher than ours. In contrast, signs in intraperitoneally treated rats were similar to ours, except salivation, erythema of skin and cyanosis. In the present study, the death occurred within 26 min after treatment and survivors recovered $6 \mathrm{hr}$ in mice and $24 \mathrm{hr}$ in rats, while intraperitoneally treated rats died $2 \sim 5 \mathrm{~min}$ after treatment, and the survivors recovered within 30 min (Glinsukon et al. 1980). These results indicate that capsaicin-induced signs are longerstanding in the oral case than in the intraperitoneal one, the disappearance being also slower in the former.

There was no abnormality found in the liver, gallbladder and kidney except for the stomach when a pathological examination was conducted

Table 2. $\mathrm{LD}_{50}$ values of capsaicin by Glinsukon et al. (1980).

\begin{tabular}{|c|c|c|c|}
\hline Animal & Sex & Route & $\begin{array}{c}\mathrm{LD}_{50}(\mathrm{mg} / \mathrm{kg}) \\
(95 \% \text { confidence limits })\end{array}$ \\
\hline \multirow{7}{*}{ Mice } & \multirow{6}{*}{ male } & Intragastric & $190(122-294)$ \\
\hline & & Intravenous & $0.56(0.36-0.87)$ \\
\hline & & Intratracheal & $1.6(1.03-2.48)$ \\
\hline & & Dermal & $>512$ \\
\hline & & Intrarectal & $>218$ \\
\hline & & \multirow{6}{*}{ Intraperitoneal } & $7.65(5.28-11.09)$ \\
\hline & female & & $6.5 \quad(4.33-9.75)$ \\
\hline Rats & female & & $9.5 \quad(5.76-18.02)$ \\
\hline Guinea pigs & male & & $1.10(0.79-1.52)$ \\
\hline Hamsters & male & & $>120$ \\
\hline Rabbits & male, female & & $>50$ \\
\hline
\end{tabular}


on the dead animals. In the stomach of both animals, focal slight erosion or ulcer was noted. It has been reported that capsaicin affects sensory neurons and consequently, vasodilation occurs as well as accelerated transition from blood vessels (Konishi, 1984). In the study of Glinsukon et al. (1980), histopathologic changes were seen only in the gastric mucosa of mice treated intragastrically with capsaicin, and associated with desquamatic necrosis with increased mucous material. Myers et al. (1987) reported that red pepper and black pepper can cause some gastric mucosal damage. In regards to the mechanism of gastric injury, it is likely that capsaicin attacked the mucosa directly, since the mucosal damage was not observed when administered via other routes and the death occurred immediately after treatment.

Furthermore, guinea pigs, mice and rats have shown a high susceptibility, whereas hamsters and rabbits were less susceptible to capsaicin (Glinsukon et al. 1980). Our results showed that mice appeared more susceptible to capsaicin than did rats. But, rats had more clinical signs and later recovery than mice. It seems likely that there is a difference in metabolism between mice and rats. According to Glinsukon et al. (1980), the lethality of capsaicin administered gastrically to mice was much less than that of the intravenous, intraperitoneal and intratracheal routes, and the acute toxicity of capsaicin as a food-borne substance in man would rarely occur. Monsereenusorn (1983) treated orally by stomach tube with capsaicin $(50 \mathrm{mg} / \mathrm{kg} /$ day) and capsicum fruit crude extract $(500 \mathrm{mg} / \mathrm{kg} /$ day $)$ to rats for 60 days, and demonstrated that there was no obvious toxicity. This lower toxicity of orally-administered capsaicin was related to its low absorption together with the rapid elimination from the body. Compared with our results, the dose which rats stood daily against dosing was very high.

In conclusion, acute toxicity of capsaicin in both mice and rats was convulsion, respiratory paralysis and stomach damage. In comparison between both species, rats had high $\mathrm{LD}_{50}$ values, more clinical signs and later recovery. Since it is very important to clarify repeat oral toxicity of capsaicin using rats in the future, the present result should become the basis for further investigation.

\section{ACKNOWLEDGMENTS}

We would like to thank Drs. Hideo Kato, Osamu Nagata and Takeo Shimo of the Research and Development Division, Hokuriku Seiyaku Co. Ltd. for the valuable advice.

\section{REFERENCES}

Agrawal, R. C., Wiessler, M., Hecker, E. and Bhide, S. V. (1986) : Tumour-promoting effect of chilli extract in BALB/c mice. Int. J. Cancer., 38, 689-695.

Glinsukon, T., Stitmunnaithum, V., Toskulkao, C., Buranawuti, T. and Tangkrisanavinont, $\mathrm{V}$. (1980) : Short communications: Acute toxicity of capsaicin in several animal species. Toxicon., 18, 215-220.

Holzer, P. (1991): Capsaicin: Cellular targets, mechanisms of action, and selectivity for thin sensory neurons, Pharmacol. Rev., 43, 2, 143-201.

Jancsó G., Kiraly E. and Jancsó-Gábor, A. (1977) : Parmacologically induced selective degeneration of chemosensitive primary sensory neurones. Nature, 270, 22/29, 741-743.

Jang, J. J., Kim, S. H. and Yun, T. K. (1989) : Inhibitory Effect of Capsaicin on Mouse Lung Tumor Development. In Vivo., 3, 49-54.

Kang, J. Y., Teng, C. H., Wee, A. and Chen, F. C. (1995) : Effect of capsaicin and chilli on ethanol induced gastric mucosal injury in the rat. Gut., 36, 664-669.

Konishi, S. (1984) : Capsaicin. SEITAI NO KAGAKU, 35 (6), 446-448.

Lille, J. and Ramírez, E. (1935) : Pharmacodynamic action of the active principles of chillie (Capsicum annum L.). Chem. Abstr., 29, 4836.

López-Carrillo, L., Avila, M. H. and Dubrow R. (1994): Chili pepper consumption and gastric cancer in Mexico : A case-control study. Am. J Epidemiol., 139, 3, 263-271.

Monsereenusorn, Y. (1983) : Subchronic toxicity studies of capsaicin and capsicum in rats. Res. Commu. Chem. Pathol. and Pharmacol., 41, 1, 95-110.

Myers B. M., Smith J. L. and Graham D. Y. (1987) : Effect of red pepper and black pepper on the stomach. Am. J. Gastroenterol., 82, 211-14.

Nagabhushan, M. and Bhide, S. V. (1985) : Mutagenic- 
ity of chilli extract and capsaicin using short term tests. Environm. Mutagen., 7, 881-888.

Serra, I. C., Báez, S. V., Endoh, K., Yamamoto, M., Calvo, A. B., Decinti, E. F., Watanabe, H., Tajima, K. and Norambuena, R. A. (1996) : Cáncer Vesicular : Estudio de casos y controles en Chile. Revista Chilena de Cirugía., 48 143-151.

Surh, Y. J. and Lee, S. S. (1995) : Capsaicin, a double-edged sword: toxicity, metabolism, and chemopreventive potential. Life Sci., 56, 22, 1845-1855.
Toda, N., Usui, H. Nishino, N. and Fujiwara, M. (1972) : Cardiovascular effects of capsaicin in dogs and rabbits. J. Pharmacol. Exp. Ther., 181, 3, 512-521.

Toh, C. C., Lee, T. S. and Kiang, A. K. (1955) : The pharmacological actions of capsaicin and analogues. Br. J. Pharmac., 10, 175-182.

Toth, B., Rogan, E. and Walker, B. (1984) : Tumorigenicity and mutagenicity studies with Capsaicin of hot peppers. Anticancer Res., 4, 117-120. 